\title{
LA ETICIDAD EN EL PROCESO DE LA INVESTIGACIÓN
}

\author{
ETHICS IN THE RESEARCH PROCESS \\ Edgar Gutiérrez Gómez ${ }^{*}$ \\ egutierrez@unah.edu.pe \\ ${ }^{1}$ Universidad Nacional Autónoma de Huanta, Ayacucho, Perú
}

*Correspondencia: Edgar Gutiérrez Gómez. Email: egutierrez@unah.edu.pe

Las circunstancias actuales ameritan aún más la inversión en la investigación científica, para coadyuvar en la sostenibilidad homogénea de la población mundial. Los recursos económicos destinados al rubro de investigación deben ser priorizados con el afán de redescubrir lo que depara la naturaleza al futuro hombre. La suntuosidad práctica ha sumido a la humanidad a una idea minimalista de su condición social. Los fenómenos mundiales de diversa naturaleza, son husmeados sigilosamente por un reducido grupo de filántropos investigadores sin fondos económicos del Estado, absolutamente relegados por las empresas privadas que lucran con las materias primas. El fenómeno actual de pandemia, obliga visionar a una sociedad como el nuevo orden mundial a partir de las enfermedades microscópicas que peligran la convivencia humana. El capital económico prima sobre todas las cosas, mientras la supervivencia del hombre aflora su sentido de existencia. Se acerca los vaticinios de que: "Lo único que necesitamos es una gran crisis internacional adecuada y las naciones aceptarán el Nuevo Orden Mundial”. (Estulin, 2005, p.197) La ganancia rentaria invadió la filantropía académica de la ciencia en todas sus áreas, limitando el cuidado ético de sus materiales de experimento; consecuentemente el producto beneficia a grupos pequeños.

La eticidad dentro de la investigación científica, es determinante para mantener esa independencia académica, en razón a los poderes de Estado e ideologías que traslucen el sesgo de la ciencia. El servicio científico que parametriza sobre un redescubrimiento de la naturaleza, de ninguna forma es exclusividad de un sector privilegiado. El conocimiento tiene una condición universal y las fuentes alimentadoras son de naturaleza infinita. Los extremos en los polos de desarrollo de una sociedad, está cicatrizado con ese conocimiento inútil de extrema utilidad en beneficio de un sector minoritario. En otras situaciones se confinan bajo el amparo de subvenciones: "Porque el tercermundismo es una filosofía, no del desarrollo, sino de la transferencia de recursos destinada a perpetuar el subdesarrollo mientras se atenúa la pobreza y, sobre todo, se palian las dificultades de tesorería de los dirigentes de la pobreza" (Revel, 1989, p.174) La transferencia de conocimientos no beneficia el progreso científico de los países en desarrollo, de igual forma menoscaba la iniciativa de los investigadores. Bajo ese parámetro se vulnera la ética del investigador, recurriendo a instrumentos y materiales producidos en serie, donde no existe el valor agregado, menos el invento y mejora de la ciencia.

Desde la tribuna de la Revista de Investigación Científica Puriq de la Universidad Nacional Autónoma de Huanta, Ayacucho-Perú. Estamos sumando esfuerzos para seguir bregando dentro de la academia de la intelectualidad, dejando de lado los intereses mezquinos de exigir al Estado; sin esmerarse en contribuir en lo mínimo a lo invertido en la ciencia, lo cual, la ética de la investigación cuestiona. Puesto que: "En esa línea se 
encuentra fomentando incentivos al quehacer académico de la investigación, en especial en las universidades públicas a nivel nacional, después de haber depurado con un proceso de licenciamiento a todas las universidades del Perú" (Gutiérrez, 2020, p.7) Seguimos apostando con trabajos de investigación multidisciplinares que la línea de la revista refleja. Es una forma de abrir un abanico de posibilidades y como vitrina de publicación para nuestros colaboradores que confían en la sostenibilidad de la Revista Puriq. Nuevamente ofrecemos en este número, artículos de investigadores heterogéneos, con sus respectivas instituciones universitarias a las cuáles representan. Como se ha indicado sobre el conocimiento inútil, en las condiciones actuales de facilismo se vale de los softwares revisores de plagio. Independientemente a la existencia y utilización de los antiplagios, debemos confiar en la eticidad del investigador y de sus fuentes con las cuáles propone sus productos hacia la comunidad científica.

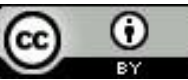

\section{REFERENCIAS BIBLIOGRÁFICAS}

Estulin, D. (2005). Los secretos del Club Bilderberg. España: Planeta, S. A.

Gutiérrez, E. (2020). Publicaciones seriadas. Puriq, 2(1). doi: https://doi.org/10.37073/ puriq.2.1.72

Revel, J. F. (1989). El conocimiento inútil. España: Planeta, S. A.

\section{CITAR COMO:}

Gutiérrez Gómez, E. (2020). La eticidad en el proceso de la investigación. Puriq, 2(2), 45-46. https://doi.org/10.37073/puriq.2.2.83 